\title{
DILEMAS ÉTICOS VIVENCIADOS PELA EQUIPE DE ENFERMAGEM NO CUIDADO PERIOPERATÓRIO FRENTE ÀS IATROGENIAS
}

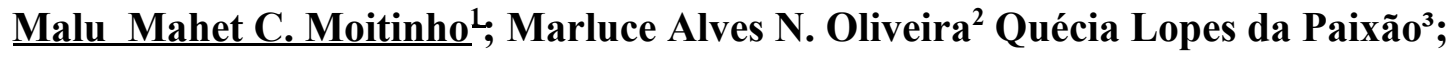 \\ 1. Bolsista PROBIC/UEFS, Graduanda em Enfermagem, Universidade Estadual de Feira de Santana, e-mail: \\ malumahet@gmail.com \\ 2. Orientador, Departamento de Saúde, Universidade Estadual de Feira de Santana, e-mail: \\ milicialves@yahoo.com.br \\ 3. Enfermeira, participante do Núcleo Interdisciplinar de Pesquisa e Estudos em Saúde, Departamento de Saúde, \\ Universidade Estadual de Feira de Santana, e-mail: quecia_lopes@hotmail.com
}

PALAVRAS-CHAVE: Ética; Equipe de Enfermagem; Cuidados perioperatório.

\section{INTRODUÇÃO}

As iatrogenias são erros cometidos pelo profissional de saúde que interferem no bem-estar do paciente (Farias, et al, 2010). A equipe de enfermagem do centro cirúrgico está propensa a vivenciar dilemas éticos frente às iatrogenias. Os dilemas éticos são situações em que existem mais de uma possibilidade de escolha, mas todas ferem princípios éticos (OLIVERA; SANTA ROSA, 2016; SILVA, et al, 2015).

A motivação para realizar esta pesquisa emergiu ao refletir sobre a temática durante práticas no componente curricular, Enfermagem na Saúde do Adulto e Idoso II, bem como a minha participação no Núcleo Interdisciplinar de Pesquisas e Estudos em Saúde, com membro do projeto de pesquisa "Vivência de conflitos e dilemas na percepção da equipe de enfermagem no centro cirúrgico". A partir da inquietação emergiu o questionamento: Como a equipe de enfermagem no cuidado perioperatório vivencia dilemas éticos frente às iatrogenias?

Este estudo tem como objetivo geral conhecer os dilemas éticos vivenciados pela equipe de enfermagem no cuidado perioperatório frente às iatrogenias e como objetivos específicos identificar o agir da equipe de enfermagem na vivência de dilemas éticos frente às iatrogenias, descrever possibilidades e limites da equipe de enfermagem vivenciar no cuidado perioperatório dilemas éticos frente às iatrogenias e estabelecer estratégias de ações para prevenção de dilemas éticos frente iatrogenias no centro cirúrgico.

\section{MATERIAL E MÉTODOS OU METODOLOGIA (ou equivalente)}

De forma a atender aos objetivos optou-se por realizar uma pesquisa com abordagem qualitativa descritiva.

As informações foram coletadas em novembro e dezembro de 2017 , por meio de entrevista semiestruturada, no CC de um hospital geral público, do município de Feira de Santana-BA. Participaram da pesquisa 6 profissionais da equipe de enfermagem que atuam no $\mathrm{CC}$, há mais de seis meses e que estivessem em atividade laboral durante a coleta de dados.

Foram realizadas três questões norteadoras: O que é iatrogenia para você? Qual a sua ação diante de dilemas éticos no cuidado perioperatório frente às iatrogenias? Fale 
sobre as possibilidades e limites da equipe de enfermagem vivenciar dilemas éticos no cuidado perioperatório frente às iatrogenias. A confidencialidade e o anonimato foram assegurados mediante uso do pseudônimo E (enfermeiros) e TE (Técnico de Enfermagem) e números conforme a ordem em que aconteceram as entrevistas.

Para a concretização do processo de análise foi utilizada análise de conteúdo de Bardin, como modo de revelar a síntese da estrutura das categorias empíricas. A análise de conteúdo é um "conjunto de técnicas de análise das comunicações” (BARDIN, 2011, p. 37).

A análise dos dados obedeceu à seguinte ordem cronológica: A pré-análise constituída pela fase de organização propriamente dita através de uma leitura flutuante dos documentos, analisando-os a fim de conhecer cada texto. A exploração do material, que consiste essencialmente em operações de codificação. A classificação dos dados foi operacionalizada através da leitura exaustiva e repetida dos textos, para através desse exercício fazer uma apreensão das estruturas de relevância a partir dos documentos pesquisados. Tratamento dos resultados, sendo realizada as inferências e interpretações a propósitos dos objetivos propostos.

O projeto foi submetido ao Comitê de Ética em Pesquisa da Universidade Estadual de Feira de Santana, CAAE: 2865214.9.0000.0053 e ocorreu em conformidade com as orientações éticas previstas na Resolução 466/12, do Conselho Nacional de Saúde (BRASIL, 2012).

\section{RESULTADOS E DISCUSSÃO}

\section{CARACTERIZAÇÃO DOS PARTICIPANTES}

Foram entrevistados 6 integrantes da equipe de enfermagem que atuam no $\mathrm{CC}$, de um Hospital Geral Público do Estado da Bahia. Destes, duas são técnicas de enfermagem e quatro enfermeiros, sendo três do sexo feminino e um do sexo masculino, com idades entre 33 a 39 anos. O tempo de formação dos entrevistados é de oito a catorze anos e tempo de atuação de seis meses a dez anos. Com carga horária de trabalho variando entre 24 a 48 horas semanais. Todos os profissionais possuem outros vínculos empregatícios e não possuem especialização em CC.

\section{COMPREENSÃO DA EQUIPE DE ENFERMAGEM SOBRE IATROGENIA}

Nesta categoria, os relatos dos profissionais da equipe de enfermagem revelam como compreendem as iatrogenias e associam com o cuidado perioperatório desenvolvido no CC e como pode desencadeá-las.

Para os entrevistados a iatrogenia está associada com erros que ocorrem no local de trabalho ao prestar o cuidado ao paciente e que podem ocasionar danos. Relacionam que os danos podem ocorrer com membros da equipe cirúrgica. As iatrogenias, proveniente do cuidado de enfermagem frequentemente tem relação à administração de medicamentos.

Os relatos corroboram com a definição de iatrogenia, que para Matos et al (2011), é o efeito indesejável decorrente de uma ação profissional que venha a 
prejudicar o processo de promoção do cuidado frente ao estado de saúde/doença da pessoa hospitalizada.

\section{CAUSA E PREVENÇÃO DE DILEMAS ÉTICOS FRENTE ÀS IATROGENIAS}

Nesta categoria, os relatos apontam os conflitos gerados pela falha na comunicação entre a categoria médica e a equipe de enfermagem como causa de dilemas frente à iatrogenias estabelecidas estratégias para a prevenção destes.

A equipe de enfermagem aponta as atitudes dos médicos como responsáveis pela relação conflituosa na unidade de $\mathrm{CC}$ relacionadas à comunicação. Contudo, ainda percebe-se que as iatrogenias podem ser prevenidas por meio do diálogo entre a equipe.

Para a prevenção desses dilemas éticos por parte da equipe de enfermagem, também é necessário o desenvolvimento da autonomia e conhecimento do Código de Ética dos Profissionais de Enfermagem, a fim de desempenhar as funções com responsabilidade e ética (OLIVEIRA, et al., 2017).

\section{FAZER/AGIR DA EQUIPE DE ENFERMAGEM FRENTE AOS DILEMAS ÉTICOS NO CUIDADO PERIOPERATÓRIO}

Nesta categoria, foi evidenciado como a equipe de enfermagem atua ao se deparar com os dilemas éticos, frente às iatrogenias, no cuidado perioperatório. $\mathrm{O}$ fato de ser integrante, ou não, da equipe de saúde em um setor faz com que profissionais possam vir a omitir situações de iatrogenias, com o receio de prejudicar nas relações interpessoais no ambiente laboral.

Nos relatos percebemos a diferente atuação dos membros da equipe de enfermagem frente aos dilemas éticos, onde a técnica tem como o agir frente às iatrogenias cometidas pelo médico, comunicar à enfermeira responsável diretamente diante dos erros que ocorrem. Já a enfermeira considera sua ação limitada, pois muitas vezes não presencia o ato.

Diante disso, nota-se que a conduta diante dessas situações pode garantir a redução de agravos à pessoa hospitalizada, desde que a assistência seja executada de forma eficiente e eficaz observando os princípios éticos e legais.

\section{POSSIBILIDADES E LIMITES PARA EQUIPE DE ENFERMAGEM VIVENCIAR DILEMAS ÉTICOS FRENTE ÀS IATROGENIAS NO CUIDADO PERIOPERATÓRIO}

Nesta categoria os profissionais destacam as situações encontradas no seu ambiente laboral que desencadeiam as possibilidades e os limites da equipe de enfermagem vivenciam dilemas éticos no cuidado perioperatório.

Acerca das possibilidades, os relatos mostram que a ocorrência dos dilemas éticos no cuidado perioperatório está atrelada à necessidade de, muitas vezes a equipe de enfermagem, precisar tomar decisão que não é da sua competência,

Quanto aos limites, foi apontada a formação em ensino superior em Enfermagem aos profissionais que atuam como Técnico de Enfermagem e o bom relacionamento entre a equipe de Enfermagem. 


\section{CONSIDERAÇÕES FINAIS}

Este estudo possibilitou conhecer os dilemas éticos vivenciados pela equipe de enfermagem no cuidado perioperatório frente às iatrogenias.

$\mathrm{O}$ estudo apontou que a equipe de enfermagem compreende iatrogenia como um erro que pode ser cometido pelos membros da equipe de saúde e durante a assistência e que muitas vezes decorrem de erros de medicação. Mostrou que as relações pessoais conflituosas são causas de dilemas no $\mathrm{CC}$, e, que para prevenir, faze-se necessário o incentivo do diálogo, a educação continuada sistematizada para a equipe cirúrgica, promovendo aperfeiçoamento do conhecimento científico e de aspectos éticos legais da profissão e desenvolvimento da autonomia.

No que concerne ao fazer e agir da equipe de enfermagem frente às iatrogenias, o estudo apontou que os enfermeiros ainda encontram dificuldades para atuar frente às iatrogenias ocasionadas pelos médicos, visto que muitas vezes as ações não são detectadas no momento em que ocorrem, sendo conhecidas de forma informal, dificultando assim a ação imediata.

Como possibilidades para vivenciar os dilemas éticos frente às iatrogenias foram encontrados os conflitos nas relações com a equipe médica e a falta de preparo dos profissionais e a inexistência de plano de cuidado para a equipe de enfermagem. Como limites o estudo apontou que os técnicos de enfermagem que tem a graduação de Enfermagem promovem cuidados diferenciados, além disso, o bom relacionamento entre os membros da equipe do centro cirúrgico leva a uma assistência de qualidade.

Concluímos que os dilemas éticos frente às iatrogenia ocorrem no $\mathrm{CC}$, mas podemos preveni-la, conhecendo as incidências e suas consequências, ressaltando a importância do conhecimento técnico e científico e dos princípios éticos e legais da enfermagem.

\section{REFERÊNCIAS}

BARDIN, L. 2011. Análise de conteúdo. São Paulo: Edições 70.

BRASIL. 2012. Ministério da Saúde. Resolução CNS 466/12. Conselho Nacional de Saúde. Comissão Nacional de Ética e Pesquisa com Seres Humanos. Disponível em: $<$ http://conselho.saude.gov.br/resolucoes/2012/Reso466.pdf $>$. Acessado em: 17/03/18. FARIAS, G. M et al. 2010. Iatrogenias na assistência de enfermagem: características da produção científica no período de 200-2009. Revista Científica Internacional Indexada. v. 13, n. 11. Disponível em: www.interscienceplace.org/isp/index.php/isp.

MATOS, L et al. 2011. A ação iatrogênica da equipe de enfermagem para a saúde do idoso. Revista Contexto \& Saúde. Ijuí. V. 10, n.20, p. 541-544. Disponível em: https://doi.org/10.21527/2176-7114.2011.20.541-544.

MINAYO, M. C. S. 2010. O desafio do conhecimento: pesquisa qualitativa em saúde. 12. ed. Hucitec. São Paulo, 407 p.

OLIVEIRA, M. A. N; SANTA ROSA, D. O. S. 2016. Conflitos e dilemas éticos: vivências de Enfermeiras no centro cirúrgico. Revista Baiana de Enfermagem, Salvador, v. 30, n. 1, p. 344-355. Disponível em: . http://dx.doi.org/10.18471/rbe.vli1.14237.

OLIVEIRA,T. A. V. A et al. Vivências de dilemas éticos pela equipe cirúrgica frente às iatrogenias. Rev enferm UFPE on line. Recife, V. 11, n. 7, p. 2795-802, 2017.

Disponível em: 10.5205/reuol.10939-97553-1-RV.1107201720. 